\title{
Social Value in Mobile Game
}

\section{A Visual Communication Design Approach in Pokemon Go Case Study}

\author{
Budi Sriherlambang \\ Visual Communication Design - School of Design \\ Bina Nusantara University \\ Jakarta, Indonesia \\ bsriherlambang@binus.edu
}

\author{
Liliek Adelina Suhardjono \\ Visual Communication Design - School of Design \\ Bina Nusantara University \\ Jakarta, Indonesia \\ lsuhardjono@binus.edu
}

\begin{abstract}
As technology improves, more and more aspects of games move closer to the human life and activities, including the way people interact and socialize with each other within their community. Pokemon Go is one of those games that utilize the social aspect of its players. This paper aims to maintain that in the process of playing Pokemon Go, the player greatly involve in a social engaging experience, and it is all possible with the help from the visual aid from the visual communication design. (Abstract)
\end{abstract}

Keywords-Pokemon Go, Social Value, Social Capital, Visual Communication Design for Game Design

\section{INTRODUCTION}

Playing game has become part of history of man, and it can even be traced back from the cave-dwelling period [1]. Both in ancient and modern times, games were played for many different purposes, from entertainment to competition to education. With the Internet entering the gaming world, the possibility of bringing game into new phase of multi direction of interaction is now increasing [2]. Internet offers more possibilities for people to interact with each other. Internet has move to user-driven control, this has invite the rise of social media platforms for people to connect, build community or publish opinion [3].

This paper aims to analyze the social value in mobile game using an approach from the visual communication design perspective, by examining the game Pokemon Go as the case study. To achieve that, this essay starts by briefly explaining the general history of the game; continue with journey of more specific game, which is Pokemon Go. It then moves forward to assess the social value of the game. The next chapter discusses the role of visual communication design for the Pokemon Go. The analysis aims to maintain that in the process of playing Pokemon Go, the player greatly involve in a social engaging experience, and it is all possible with the help from the visual aid from the visual communication design discipline.

\section{RESEARCH METHOD}

This research is based on a qualitative method, specifically case study method. It examines the social value in the game
Pokemon Go, and how the roles of visual communication design within the game itself. The observations were done on several official websites related to Pokemon Go, as well as literature in the field of game, visual communication designs, social capital and value networks. More than five internetbased forum dedicated to Pokemon Go fans had been observed, and some interviews with Pokemon Go players had also been conducted along the way.

\section{THE HistORY OF GAME}

The video game entered the digital format when a game called Spacewar! was created by an MIT student in 1961 named Steve Russel [4]. Two decades ago, Nintendo created the original Pokemon game franchise, that has sold more than 200 million copies over the past two decades [5]. After that more games were created until today with key aspects of involving players in artificial conflict, following specific game rules and there will a countable result [6].

Fast forward to the $21^{\text {st }}$ Century, the potential of games in social media platforms has been seen since 2010, when Facebook have 350 millions active users, $53 \%$ or more than 175 millions of them are playing games and 19\% of them said they are addicted [7]. This addiction also stated by Whitbourne, that said that online games are fun and can become addiction. In correspondence to that, casual games players of online games are playing the game for social reason [8]. Furthermore, the social interaction in playing online games can leads to social capital [9], [10].

Pokemon journey as a game has gone through several phases. First it was launched as a game in 1996, and then there are number of different 'generations' a different era of the game and the monsters, introduced into the market. There were also different format of Pokemon as in game, manga or Japanese comic, trading cards and movies. In the game environment, Pokemon has enter almost every game consoles mainly created by Nintendo, Game Boy, Game Boy Advance, Nintendo 64, Nintendo Wii, Nintendo DS and even more game consoles created by other manufacturers [11]. Following the success of the game, movies and trading cards, some official Pokemon Centers are opened to give physical experience and merchandise for the Pokemon fans. 


\section{Pokemon Go as a Game with Social Value}

In the era of digital realm, Pokémon Go is a free-to-play, location-based augmented reality game developed by Niantic for iOS, Android, and Apple Watch devices. It was initially released in July 2016, and were daily played by 20 million active users in the US alone, by the time of this research [12].

Initially started as a childhood hobby of a person named Satoshi Tajiri of catching insects and tadpoles. He decides to share his fondness to practice by bringing it to share it with other people to have similar experiences. To start sharing the idea, a game company was established under a name of Game Freak. The idea of creating small sized monsters inside a container was then created, it called Capsule Monsters. Nintendo as one of the pioneer and biggest game company in Japan, comes in to give fund for the Capsule Monsters, due to the copyright issue, the game's name then changed into Pocket Monster, abbreviation of the game we know today as Pokemon [13]. For Nintendo, Pokemon has become the second biggest game ever managed after the Mario Bros game, originally made by and exclusively for Nintendo.

The latest version of Pokemon game is Pokemon Go, which is launched on July 2016. Pokemon Go created to be played on mobile devices, a continuous franchise development enters the industry of mobile games. Pokemon Go is created by Niantic Labs, which was owned by Google, who created a similar location based game that becomes popular few years back, Ingress.

Pokemon Go is a real-world social-network game that combines the real world and the fun and imaginative creatures of Pokemon. The game play functioned as part exercise since the player needs to walk so the game will read the smartphone GPS to find a Pokemon monsters located in specific areas. When a player encounter a Pokemon, the player have to tap on the Pokemon to capture it using Poke Ball. The Pokemon will appears as it is real in the real-world looking through a smartphone by using augmented technology. The real situation of the real-world environment is apparent when the Pokemon creatures entering the human space, whether it is indoor or outdoor.

After a Pokemon being captured, it will be stored inside a Poke Dex, a special device to keep all Pokemons that the player have caught. The other factor that is important to mention is how in the Pokemon Go, the player have to choose one team only from 3 teams available. Even though a player could change their team, but it will be more beneficial for them to stick with one team. To make people interested in the concept of different team and to make them joining a team is by creating different characteristic of a team available. Becoming a team member is a must when a player reach level 5 of experience, the experience level was based on how many Pokemon you have captured. When a player reach level 5 and join a team, the player can enters a Poke Gym to battle against other persons Pokemon. The rewards of this is if a player's Pokemon could defend a gym for several amount of time, 20 hours as far as this research, they will receive items that is useful for their next journey in collecting Pokemon. Pokemon Gym are spreaded all over the maps along with the Poke Stop, the Poke Stop provide more simple reward compared to defending a Poke Gym.

The last thing that is important is the fan base of Pokemon that moves the game faster in becoming one of the fastest popular game in history. With a lot of history proven succesess that Pokemon has, it is clear that Pokemon already have a fan base that are waiting new Pokemon video game launches. In the first day, Pokemon Go reached number 7 of Apple free apps for game category.

The combinations of new approaches in playing games plus the new opportunities provided by the internet has created a game that can contribute to the company share value increase fo $86 \%$ or adding US $\$ 19,5$ billion to Nintendo company value only in 1 week since it launches [14]. With strong social approach of Pokemon Go, the value of the game would be also contributed by the social capital. The social capital formed by the interaction between the different actor in playing the game [15].

In today connected society, human have more possibilities and control of what they are interested to engage further. Ramirez argue that the value creation process is more multi direction and synchronous, a contrary to what happens during the industrial era where the consumers is merely destroying a value rather than creating it [16]. In playing Pokemon Go, the user has the freedom to walkthrough in the virtual world that still attached to the real world by using GPS. Players can also co-creating the value of the Pokemon Go while they are playing together in the real wolrd when they are interacting with other player, which invites more dialogue. This situation enhances the dialogue and knowledge sharing that each Pokemon fans already did before the Pokemon Go [17].

There is a tangible value exchange that actively happening between users of Pokemon Go [18]. The value is not measured by a value of money but in value of knowledge. A knowledge that actively been shared thorough different Internet platforms, social medias, websites and forums has created an enormous value for the Pokemon Go.

The experience that the players felt also become one of the value that needs to be considered, since the economy is moving towards experience economy where an experience is becoming more valuable and expected more than tangible or commodity [19]. Pokemon Go gives experiences that have never before been felt by the Pokemon's fan, or other people who are not a Pokemon trainer per se, but nonetheless are a smartphone user. The Pokemon Go fans undergo 4 stages of consumer experience, which contribute to the rising number of Pokemon Go users [20]. Firstly, the pre-consumption experience, the rumors spreading and the jokes arise about Pokemon game will be available in smartphone has built a high expectation. Secondly, the purchasing experience: the easiness of having Pokemon Go as a free mobile application from the developer. In this case, Niantic has become an excellent service provider for the users. Thirdly, the core consumption experience: the new approach in video games, using high-specs smartphone with a nice looking visual, which provide comfort and complete visual arrangement, and also the clear visual communication design enriching the experience to the gamers. Finally the fourth, the nostalgic experience, the previous 
experience of playing Pokemon has become more relevant and delivered in most interesting and update way of technology. The world of Pokemon has created a strong narrative that constructs a new world that stays in the user minds and can develop the narrative to further invite other people to join the conversation [21].

Pokemon Go gameplay and experience has created a generative process that is beneficial for both the company and its user. It is the success of the company who makes Pokemon Go as a public property that can be played by everyone with the necessary gadget [22]. There is an ongoing process of value co-creation between the user and the company. Technology advancement in Internet and communication also provides an opportunity to invite more people playing Pokemon Go. The Internet has created an interlinking society that makes people more connected than before [23]. This has allowed people to contribute more to the games' value, through their social capital to interact and influencing the value creation process [24]. The networked society has created new consumers with their own behavior in using and interacting with products and services. Where the new consumers are more value conscious, focusing in his own identity, looking for self-expression, meaning and quality in life [25].

\section{ANALYSING THE VISUAL COMMUNICATION DESIGN ON THE POKEMON GO}

At its core, visual communication design (also known as graphic design) is result of a creative process in order to communicate ideas, using the combination of visual arts and technology. It is about communicating with people such as audiences, readers, users, visitors, and of course, game-players [26]. Using visual communication design, verbal messages are altered into visual, by controlling its design elements, which are lines, shapes, colours, textures, and in the case of digital game design, characters and movement. Color, image and composition have the power to create visual mnemonics, both individually and collectively [27]. For Pokemon Go, the basic design elements are generally using vivid and bright colors, which primarily used in many casual games. The use of this set of colors also suggest a happy environment, in line with the mood of the game which are full of spirit and energy, telling us to keep on moving chasing the Pokemons. The use of distinctive colors also helps the categorizations of the team divisions, once the player reach the fifth level: red for team Candela, blue for team Blanche, and yellow for team Spark (figure 1).

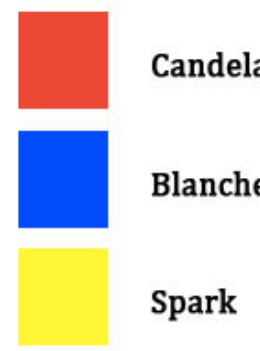

Fig. 1 Color swatches for the different Pokemon Go teams
The layout of the Pokemon Go subscribe to a simple symmetrical balance. The whole screen is divided into two equal area, left and right (figure 2). This simple division eases the player's eyes, as every important fragments of information are directly presented to them.

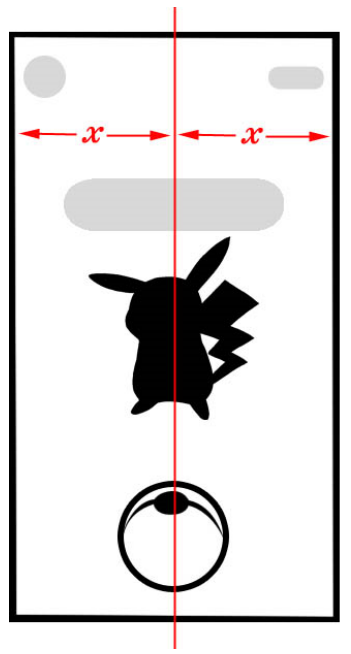

Fig. 2 The symmetrical balance on the Pokemon Go screen display

Another essential layout principal in this game is the sequence/hierarchical flow of the design elements/objects. Sequence holds a vital role, because if all the objects are presented in an equal intensity, the audience will have to struggle in catching all the information on the display [28]. The hierarchical sequence in the Pokemon Go display is generally simple (figure 3). Although there are several different information presented at once, however, with the clever use and emphasize on the image size, color intensity, and various typographical point size, it is not difficult for the Pokemon trainer to sum up all the information in a short period of time. As we can see on the figure 3, there are several groupings on the layout, which automatically leads our eyes to read every element on the group at the same time. This arrangement helps the player to capture the essential information on the display.

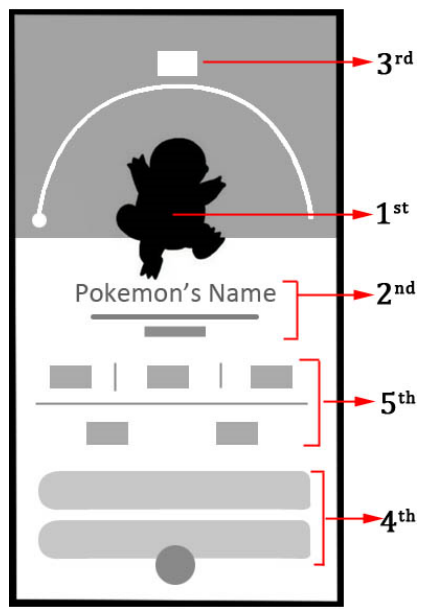

Fig. 3 Hierarchical sequence on the Pokemon Go screen display 
While conventional visual communication design weightily rely on the existence of interfaced, innate software; one of the many thrilling outcomes of digital design is the integration of the design skills and programming dexterities, which results in new hybrid areas of interdisciplinary collaborations. Visual communication design is becoming progressively interdisciplinary and collaborative [29]. These collaborations shows heavily on the Pokemon Go's user interface, where it comprises on several different elements such as main character (the player), secondary character (the Pokemon creatures), environment which using GPS technology, building which are functioning as Poke Stop and Poke Gym. For the first time, Pokemon Go enthusiasts are uncovering the enjoyment of playing a game that takes them to surrounding landmarks and unpredictable points of interest, all in the name of collecting rare monsters [30]. Some say they're exploring their neighborhoods more than ever and noticing new spaces that were not normally exist on their routine journeys. There's also an excitement that arises from knowing strangers on the street who happen to play the very same game. These explorations are all possible with the guide from the visual signage on their gadget.

Pokemon Go has hundreds of characters, which evolve according to their power level. Starting from some cute looking creatures, they can evolve into some gigantic gruesome monsters (figure 4). These physical evolutions show the use of visual wit or shock, which have the ability to evoke responses of laughter, astonishment, horror or even antipathy; all of which require interaction with the audiences' perception [31]. However, even when the harmless-looking creatures change their visual appearance into some big abhorrent monster, they still retain some common threads, which suggest that they are indeed share the same roots. A visual mnemonic can be something that is instantly recognizable at the first glance, but sometime it demands a visual trigger to fuel the player's recollection. The most frequent tool as the recognition trigger is, once again, colors. The use of distinctive color set was proved to be an effective instrument to make a memorable design. [32].

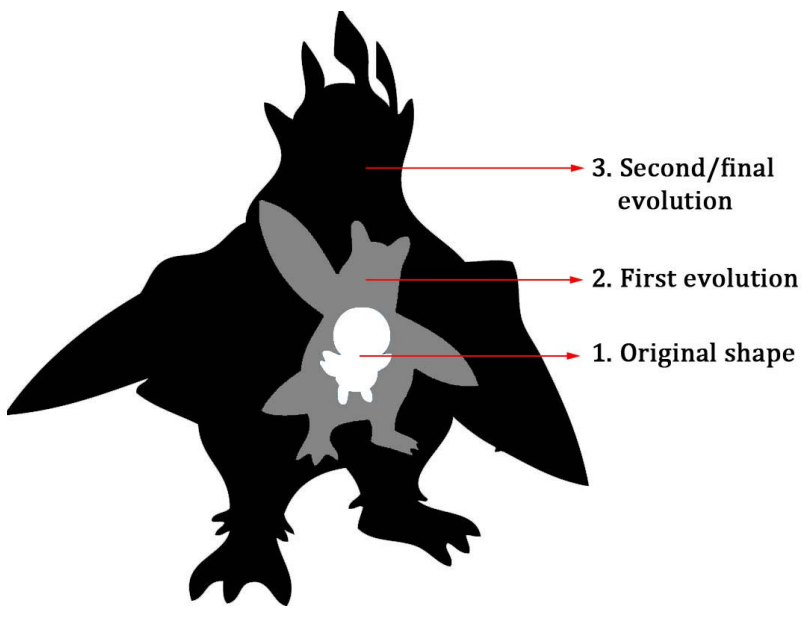

Fig. 4 Pokemon Go Evolution
One of the utmost effects on Visual communication Design that the computer has made was the dawn of 3D design. While graphic designers have always been tangled in 3D design, such as in the use of typographic elements and in architectural rendering, the virtual 3D setting has prominently amplified the involvement of visual communication designers, which encompass the expertise on story-telling, scenarios, storyboard, lighting, and character modeling, and many more. In Pokemon Go, this 3D element has made the boundary between the virtual world and the reality became blurred. Because what appears in the mobile screen correspond in real time with the move of the players, whether they chase, encounter Pokemon, battling in a gym, and so on. Therefore the visual communication designer responsible to direct the player, becoming their visual aid in order to reach their mission.

\section{CONCLUSIONS}

Game design plays an important role in making a game interesting. The manner in which audiences' visual perception is entertained could potentially make players amused, so that they can play for longer period of time. Therefore, the visual composition in the game interface needs to be effectively designed.

The role of visual communication design can enhance the experience of the player. The use of a fitting visual communication design will attract game user to download and play the game, inform and persuade them to involve with the challenge, and entertain them with a visually engaging eye candies. However, the layout for a mobile game itself does not need to be intricately sophisticated. A simple layout will be adequate as long as the information regarding the game mission are presented in a clear and easy-to-understand manner. The simple layout has even proven to be beneficial for the Pokemon Go trainers, as this type of layout arrangement helps the player to capture the essential information on the display, without any unnecessary distraction.

To take the chance of engaging themselves in a fantasy world of game gives people some opportunities to immerse themselves with their surrounding. Pokemon Go is definitely one of the mobile games with a high social value, where people are actually urged to do that. It will be a stretch to claim that visual communication design is directly, and/or singlehandedly responsible to this high level of social value. However, by utilizing a good and effective visual communication design, Pokemon Go indeed gained some advantages. The player will only take that risk, whenever they feel attracted by the visual appearance of the game in the first place. More importantly, a good design plays a vital role in order to make the player understand the rules of the game easily. In other words, visual communication design becomes a visual aid to the player so that they can involve in a social engaging experience whenever they play Pokemon Go. And naturally, the more people play the game, the higher social values that they gain. 


\section{REFERENCES}

[1] E-N. Simon, J. Smith Heide, and S. Tosca Pajares Understanding Video Games: The Essential Introduction. 3rd ed. New York: Routledge/Taylor \& Francis Group, 2016.

[2] R. Ramírez, "Value co-production: intellectual origins and implications for practice and research", Strategic Management Journal, vol. 20, no. 1, pp. 49-65, 1999.

[3] T. Smith, "The Social Media Revolution", International Journal of Market Research, Vol 51, Issue 4. 2009.

[4] S. Kent, The ultimate history of video games. Roseville, Calif.: Prima Pub., pg. xi-xvi. 2001.

[5] B. Winegarner, "Forget Pokémon Go, there's another augmented reality game that's way better", Quartz, 2016. [Online]. Available: http://qz.com/732809/forget-pokemon-go-theres-another-augmentedreality-game-thats-way-better/. [Accessed: 20- Oct- 2016].

[6] K. Tekinbaș and E. Zimmerman, Rules of play. Cambridge, Mass.: MIT Press, 2003.

[7] T. McCollum. "Incredible Facebook Game Facts". October 20, 2010. [accessed on 18 September 2016]

[8] S. Whitbourne, "Those Facebook Games We Play and Why We Play Them", Psychology Today, 2016. [Online]. Available: https://www.psychologytoday.com/blog/fulfillment-anyage/201401/those-facebook-games-we-play-and-why-we-play-them. [Accessed: 18- Sep- 2016].

[9] C. Safferling. "Social Capital and Online Games". Working Paper Series 2011-32, September 2, 2011.

[10] J. Yang. Social Capital in Social Network Games. Proc. of Human and Social Sciences at the Common Conference (HASSACC), November 18-22, 2013 Karlsruhe, Germany. Institut Für Regionalwissenschaft. [accessed on 18 September 2016]

[11] Bulbapedia. 1 September 2016. [accessed on 18 September 2016]

[12] DMR (2016) 57 Amazing Pokémon Go Stats [online]. Available from: http://expandedramblings.com/inded.php/downloads/dmr-pokemon-gostatistic-report/ [Accessed: 17 September 2016]

[13] Bulbapedia. 1 September 2016. [accessed on 18 September 2016]

[14] Z. Rodionova, "Pokémon Go has added $£ 15 \mathrm{bn}$ to the value of Nintendo in a week", The Independent, 2016. [Online]. Available: http://www.independent.co.uk/news/business/news/pokemon-go- ninetendo-apple-google-share-price-market-value-a7138426.html. [Accessed: 18- Sep- 2016].

[15] E. Lesser, Knowledge and social capital. Boston: ButterworthHeinemann, 2000.

[16] R. Ramírez, "Value co-production: intellectual origins and implications for practice and research", Strategic Management Journal, vol. 20, no. 1, pp. 49-65, 1999.

[17] E. Lesser, Knowledge and social capital. Boston: ButterworthHeinemann, 2000.

[18] V. Allee, "Reconfiguring The Value Network", Journal of Business Strategy, vol. 21, no. 4, pp. 36-39, 2000

[19] B. Pine and J. Gilmore, The Experience Economy. Boston: Harvard Business School Press, 1999.

[20] E. Arnould, L. Price and G. Zinkhan, Consumers. Boston: McGrawHill/Irwin, 2004.

[21] D. Zandee. Poetic language, poetic activism. Nyenrode Business Universiteit. the Netherlands, 2010.

[22] E. Lesser, Knowledge and social capital. Boston: ButterworthHeinemann, 2000.

[23] D. Buhalis, eTourism: Information Technologies for Strategic Tourism Management (1 ed.). Harlow, England: Financial Times Prentice Hall, 2003.

[24] C. Prahalad and V. Ramaswamy, "Co॰creating Unique Value with Customers", Strategy \& Leadership, vol. 32, no. 3, pp. 4-9, 2004.

[25] K. Jager. New Consumer. Breda: NHTV Imagineering Academy. 2010.

[26] A. Twemlow, What is graphic design for?. Singapore: RotoVision SA, 2006.

[27] C. Knight and J. Glaser, Sticky graphics. Singapore: Page One, 2006.

[28] S. Rustan, Layout Dasar \& Penerapannya Edisi 2014. Jakarta: Gramedia Pustaka Utama, 2014.

[29] A. Twemlow, What is graphic design for?. Singapore: RotoVision SA, 2006.

[30] B. Winegarner, "Forget Pokémon Go, there's another augmented reality game that's way better", Quartz, 2016. [Online]. Available: http://qz.com/732809/forget-pokemon-go-theres-another-augmentedreality-game-thats-way-better/. [Accessed: 20- Oct- 2016].

[31] C. Knight and J. Glaser, Sticky graphics. Singapore: Page One, 2006.

[32] C. Knight and J. Glaser, Sticky graphics. Singapore: Page One, 2006. 